\title{
Questes
}

Revue pluridisciplinaire d'études médiévales

\section{Les activités quotidiennes au Moyen Âge : conclusion}

Cécile Le Cornec

\section{(2) OpenEdition}

1 Journals

Édition électronique

URL : http://journals.openedition.org/questes/4121

DOI : 10.4000/questes.4121

ISSN : 2109-9472

Éditeur

Les Amis de Questes

Édition imprimée

Date de publication : 15 septembre 2008

Pagination : 92-94

ISSN : 2102-7188

\section{Référence électronique}

Cécile Le Cornec, "Les activités quotidiennes au Moyen Âge : conclusion », Questes [En ligne], 15 2008, mis en ligne le 01 janvier 2014, consulté le 15 septembre 2020. URL : http:// journals.openedition.org/questes/4121

\section{(C) Association des amis de «Questes »}




\section{Conclusion}

\section{Cécile LE CORNEC ROCHELOIS}

Le rêve d'une restitution exacte du quotidien est à l'horizon de nombreux travaux d'histoire. Ne s'agit-il pas d'un mirage ? Les habitudes, les gestes, les désirs, les peurs et les joies qui rythmaient la vie des hommes du passé ne nous échappentils pas irrémédiablement? Si l'apport de l'archéologie a permis un profond renouvellement des recherches dans le domaine de la culture matérielle, donnant accès à des détails et à des classes sociales ignorés des textes, l'aperçu que nous procurent les seuls vestiges matériels est nécessairement partiel. Quant aux textes littéraires, ils procèdent à une recomposition du réel soumise à des codes propres à chaque genre, à chaque auteur et à chaque œuvre. Le dialogue déjà bien engagé entre archéologues, historiens et littéraires, qui seul permet d'éclairer ce qui au premier abord parait inaccessible, s'est une fois encore révélé au cours de ces séances des plus productifs.

Les interventions des historiens et des archéologues nous ont prouvé combien le quotidien des hommes du Moyen Âge demeurait un champ ouvert aux explorations nouvelles et aux découvertes. L'étude des comptes des reines de Sicile déjoue les préjugés: Marion Chaigne a montré qu'outre la gestion des dépenses somptuaires et domestiques, ces nobles dames assument d'importantes responsabilités sociales et financières, en particulier en temps de guerre. La méthode exposée par Yann Morel pour analyser les comptes bourguignons nous a donné un aperçu de la finesse des résultats que l'on peut attendre de telles recherches. L'histoire de l'alimentation ne se borne plus alors à des données quantitatives; elle nous donne accès à des réalités aussi évanescentes que les modes ou les sensibilités médiévales. L'ouvrage de Danièle Alexandre-Bidon, Une archéologie $d u$ goût : céramique et consommation, en a fourni une éclatante démonstration. 
Envisageant les pots en céramique sous l'angle de la consommation et non de la production, l'auteur a mis en évidence, à travers la confrontation des données archéologiques, des actes de la pratique et de textes scientifiques et littéraires, l'attirance des hommes de ce temps pour le goût de terre. Des compétences multiples sont nécessaires à ce type de travail, comme l'a confirmé l'exposé de Catherine Mousinho sur l'histoire des ruches et du métier d'apiculteur. Relevés sur le terrain, analyses des données, exploitation raisonnée des divers documents écrits et de l'iconographie permettent de reconstituer les techniques et les gestes d'autrefois.

De telles avancées ne sauraient être indifférentes à ceux qui se consacrent aux analyses littéraires. Les realia constituent un matériau de premier ordre pour les auteurs comiques médiévaux. Des textes tels que les fabliaux ou le Roman de Renart nous invitent à de constantes confrontations avec les résultats des historiens et archéologues afin de séparer les efforts de reproduction du réel des effets de distance. Les histoires de ces personnages amusaient certainement d'autant plus qu'elles rappelaient les activités de tous les jours ; mais on sait que la déformation est un puissant ressort comique et divers jeux de décalage interdisent d'accorder à ces textes une valeur documentaire. Les contributions littéraires ont montré que cette problématique s'applique aussi aux « genres sérieux ». Si la littérature courtoise ne développe guère les références à la vie de tous les jours, les mentions occasionnelles des métiers ou des tâches ordinaires y acquièrent une résonance singulière. Laurence Élisa Cousteix a illustré ce caractère éminemment signifiant du quotidien figuré dans les romans en prenant l'exemple du filage. Les tisseuses arthuriennes sont celles qui savent nouer et dénouer les fils du destin, au point que l'activité ordinaire de ces Parques médiévales en fait de sérieuses concurrentes pour le narrateur en quête de légitimité. La métaphore associée au tissage est si prégnante que les conteurs préfèrent évacuer cette activité quotidienne. Les rythmes du quotidien trouvent en revanche toute leur place dans les dits amoureux du XIV siècle. En soulignant la manière subtile dont les conteurs ancrent leurs récits dans 
une temporalité fortement ritualisée, Laetitia Tabard a suggéré l'évolution qui se dessine vers la fin du Moyen Âge : une attention croissante portée aux gestes et aux choses de tous les jours, qui fournissent aux auteurs des genres nobles une nouvelle matière romanesque.

Des écrous bourguignons aux narrations en vers, la représentation du quotidien est caractérisée par quelques constantes. Aux listes des comptables répondent par exemple les longues énumérations des dits ou des romans. Certains conteurs n'hésitent pas à suspendre la temporalité linéaire du récit pour inventorier les métiers ou les objets de tous les jours, évoquant ainsi un arrière-plan familier. L'expression du quotidien passe alors par l'accumulation plutôt que par la répétition. À travers le thème des activités quotidiennes, l'exotisme irréductible du monde médiéval par rapport au nôtre affleure dans toute son étrangeté. L'écart n'est pas exclusivement d'ordre matériel. Il tient aussi aux structures religieuses et sociales, aux sensibilités et aux représentations. C'est peut-être en scrutant le quotidien médiéval, et avec lui la culture matérielle de cette époque, que nous touchons au plus près cet autre Moyen Âge, susceptible d'éclairer nos propres usages et mentalités. 